\title{
Capacidades tecnológicas da indústria farmacêutica brasileira: uma análise dos efeitos dos financiamentos do BNDES e da Finep
}

\author{
Igor F. Bueno (PPGE - Departamento de Economia / \\ Universidade Federal Fluminense - UFF); \\ Marco A. Vargas (Departamento de Economia / \\ Universidade Federal Fluminense - UFF).
}

\section{Resumo:}

A indústria farmacêutica é tradicionalmente classificada na literatura como um oligopólio baseado em conhecimento, sendo sua dinâmica função direta dos investimentos em pesquisa, desenvolvimento e inovação. Este artigo se propõe a analisar de forma integrada o impacto dos financiamentos com créditos subsidiados concedidos pelo Banco Nacional de Desenvolvimento Econômico e Social (BNDES) e pela Agência de Brasileira de Inovação (Finep) sobre a criação de novas capacidades tecnológicas nas empresas farmacêuticas brasileiras, entre os anos de 2006 e 2018. A avaliação qualitativa sobre os efeitos dos recursos na constituição de competências técnicas é feita ao nível da firma, por meio das informações dos projetos financiados pelas instituições de fomento e pelos indicadores produzidos a partir da pesquisa de inovação brasileira. A conclusão é de que os créditos públicos para inovação contribuíram para modernizar o parque produtivo e, em menor escala, para as empresas alcançarem melhores níveis de capacidades tecnológicas.

Palavras-chave: financiamento da inovação; capacidades tecnológicas; indústria farmacêutica.

Código JEL: O38. L52. L65. O14.

Área Temática: 1. Indústria, produtividade e competitividade; 1.1. Dinâmicas industriais setoriais e dos sistemas de produção 


\section{Introdução}

No âmbito da abordagem neoschumpeteriana, o Estado desempenha um papel central na consolidação e fortalecimento dos Sistemas Nacionais de Inovação (FREEMAN, 1982; LUNDVALL, 1992), a fim de promover processos de desenvolvimento econômico e tecnológico. Nesse tipo de abordagem, a intervenção do Estado não é vista como uma resposta às falhas do mercado, mas como uma resposta às falhas sistêmicas, tendo a capacidade também de criar e moldar o mercado (CHAMINADE; EDQUIST, 2010; MAZZUCATO, 2018). As políticas de inovação refletem a crescente consideração de que o conhecimento e a inovação são fundamentais para o desempenho econômico nacional (CHAMINADE; LUNDVALL, 2019). Nessa perspectiva, List (1904) já havia argumentado que a política econômica, incluindo a política comercial, deve estar concentrada em intervenções que fortaleçam a base de conhecimento nacional.

O financiamento das atividades de inovação continua sendo um ponto de debate entre os estudiosos da área, uma vez que os bancos privados e os mercados de ações são avessos a esse tipo de investimento. A natureza do processo de inovação, tal como o longo prazo de maturação, a incerteza e o risco, indica a necessidade da existência de arranjos institucionais nacionais (MELO, 1994). Entretanto, no Brasil, observa-se que, de uma maneira geral, o sistema financeiro atua sem qualquer influência no que diz respeito ao desenvolvimento do mercado de capitais e do crédito bancário privado para financiar ativos intangíveis. Como consequência, o Banco Nacional de Desenvolvimento Econômico e Social (BNDES) e a Agência Brasileira de Inovação (Finep) foram criados a partir da ação estratégica do Estado. Dentre outras funções, eles assumem a intermediação financeira com o sistema industrial no financiamento da inovação, alocando recursos públicos nos mais diversos setores da economia.

O objetivo do artigo é avaliar o impacto das políticas de fomento à inovação sobre o processo de acumulação de capacidades tecnológicas da indústria farmacêutica brasileira. Para isso, o trabalho analisa os esforços de inovação empreendido por essas empresas, à luz dos instrumentos de políticas operacionalizados pelo BNDES e pela Finep, com destaque para o crédito com taxas subsidiadas. A hipótese desta pesquisa é que as empresas farmacêuticas financiadas pelas duas instituições de fomento foram capazes de transformar os recursos recebidos em novas competências técnicas. Isso pode ser explorado por meio dos investimentos realizados nos projetos financiados e da trajetória dos esforços de inovação. A questão central refere-se a qual foi o papel do financiamento dos projetos de inovação no processo de aquisição de conhecimento.

A indústria farmacêutica é reconhecidamente intensiva em tecnologia e baseada em ciência (GADELHA; VARGAS; MALDONADO, 2013). Para que novos produtos sejam desenvolvidos, é necessária acumulação tecnológica, isto é, capacidade de gerar e modificar tecnologias existentes (BELL; PAVITT, 1995). Essas competências são construídas ao longo de muitos anos de investimento em conhecimento e em atividades de inovação. Esse tipo de indústria combina interesses econômicos relacionados ao retorno dos investimentos em tecnologias estratégicas, com uma dimensão sociossanitária referente à agenda de saúde de um país. Assim, ter esse segmento forte torna-se necessário, principalmente em momentos de conjunturas instáveis e incertas em que os mercados se fecham e criam dificuldades comerciais e de cooperação.

O setor farmacêutico ocupou um lugar de destaque nas políticas industriais e de inovação implementadas no Brasil, a partir dos anos 2000. O fortalecimento das empresas desse setor foi precedido da ocorrência de algumas mudanças importantes no arcabouço regulatório e institucional: a sanção da Lei da Propriedade Industrial ${ }^{1}$, a estruturação de um ambiente regulatório estável e confiável, por meio da criação da Agência Nacional de Vigilância Sanitária $^{2}$ (Anvisa) e a promulgação da Lei dos Genéricos ${ }^{3}$. Tais fatos contribuíram, no decorrer das duas últimas décadas, para um processo de transformação estrutural das empresas.

O Brasil possui um mercado farmacêutico expressivo, que fatura $\mathrm{R} \$ 76,20$ bilhões e ocupa a sétima posição no ranking mundial (ANVISA, 2019; INTERFARMA, 2019). Em linhas gerais, esse mercado está dividido em varejo (70\% de participação) e institucional (30\% de participação), sendo que esse último se refere às vendas para o governo, as clínicas, os hospitais e os planos de saúde. Os medicamentos novos (ou de referência) têm a maior participação no mercado, com $37 \%$ das vendas, considerando o faturamento do setor em 2018. Os similares e os genéricos somados respondem por $35 \%$ do mercado, enquanto os medicamentos biológicos representam $22 \%{ }^{4}$ (ANVISA, 2019). Ainda nesse contexto de mercado, cabe destacar a situação de vulnerabilidade da balança comercial do país, que aumenta de maneira gradual o elevado saldo negativo, ano após ano, resultando em um déficit de US\$ 5,8 bilhões no ano de 2018 (COMEXSTAT, 2019).

\footnotetext{
${ }^{1}$ Lei $\mathrm{n}^{\circ} 9.279$, de 14 de maio de 1996.

${ }^{2}$ Lei $n^{\circ} 9.782$, de 26 de janeiro de 1999.

${ }^{3}$ Lei $n^{\circ} 9.787$ de 10 de fevereiro de 1999.

${ }^{4}$ Os outros produtos são os específicos e os radiofármacos, que representaram $6 \%$ do mercado, também em termos de faturamento.
} 
Além dessa introdução, o artigo está organizado da forma descrita a seguir. Na segunda seção, é feita uma revisão teórica referente às características do financiamento das atividades de inovação. A terceira seção trata da metodologia, baseada em uma análise qualitativa dos dados no que se refere aos contratos de financiamento e aos indicadores dos esforços de inovação. A quarta e quinta seções apresentam os resultados dos apoios concedidos pelo BNDES e pela Finep para o setor farmacêutico e analisam os dados da Pesquisa de Inovação Brasileira (Pintec), produzida pelo Instituto Brasileiro de Geografia e Estatística (IBGE). Ao mesmo tempo, nessas seções, são feitas discussões acerca das consequências do suporte público sobre o processo de acumulação de capacidades tecnológicas das empresas desse segmento industrial. Por fim, a sexta seção traz as principais conclusões do artigo.

\section{O financiamento da inovação e as capacidades tecnológicas}

A literatura de Sistema Nacional de Inovação forneceu uma nova compreensão da inovação como um processo sistêmico e interativo, sendo parte integrante e fundamental das estratégias de desenvolvimento de um país (FREEMAN, 1982; LUNDVALL, 1992). O processo de inovação, entendido como o principal vetor do desenvolvimento, foi definido não somente como um ato isolado, mas também como um processo de aprendizado não linear e cumulativo de conhecimento (CASSIOLATO; LASTRES, 2005). Nesse contexto, o financiamento da inovação pode ser analisado como um subsistema dos sistemas nacionais de inovação, considerado como uma instituição central e podendo ser um dos diferenciais na configuração e no desempenho dessa estrutura (EDQUIST, 2006). Apesar da evolução no entendimento do processo de inovação, essa literatura avançou pouco no que se refere à incorporação da dimensão financeira em sua análise (RAPINI, 2010; O'SULLIVAN, 2006). Discutir as especificidades do financiamento da inovação caracteriza-se como um aspecto relevante para o desenho de políticas de promoção do desenvolvimento industrial.

O financiamento para os investimentos em inovação ainda é um gargalo estrutural não solucionado pelas instituições privadas. A natureza desses investimentos, tais quais o longo prazo de maturação, a incerteza do resultado e a questão da apropriação do conhecimento, mantém ainda o debate sobre a necessidade de arranjos institucionais específicos (ARROW, 1962; CHRISTENSEN, 1992; MELO, 1994). Investir em inovação implica assumir uma incerteza maior do que em investimentos tangíveis, os quais já incorporam os conhecimentos tácitos codificados em manuais técnicos de operação (MELO, 2009).

Rosenberg (1990) destacou que o financiamento deve ser estruturado para atender ao requisito de elevada incerteza da pesquisa básica; entretanto, quando o resultado do investimento é alcançado, o retorno social é elevado e apropriado pelas empresas com retornos privados significativos. Freeman e Soete (2008) avançaram na discussão a respeito da incerteza no âmbito do processo de inovação, descrevendo três tipos de incertezas, conforme a sua natureza: (i) técnica, se referindo ao grau de satisfação propiciado pelo resultado do desenvolvimento no atendimento de uma variedade de critérios técnicos; (ii) de mercado, relacionada às dificuldades de se prever a reação dos concorrentes e dos consumidores; (iii) e incertezas gerais da economia, presentes em todos os investimentos que envolvem resultados futuros. Esses autores concluíram que o mercado possui pouca intenção em financiar as atividades de pesquisa e desenvolvimento, exceto em alguns momentos quando a incerteza é baixa ou quase inexistente. Assim, o financiamento da inovação acaba sendo realizado por meio da utilização dos lucros da própria empresa ou por meio do financiamento concedido pelo Estado (RAPINI, 2010).

A incerteza é, portanto, um dos principais fatores inibidores da inovação, no entanto o Estado é capaz de aplicar medidas de políticas econômicas, minimizando essa condição adversa (ERBER, 1980). As características institucionais dos sistemas financeiros são consideradas fundamentais para decisão das firmas investir em inovação. O sistema financeiro caracteriza-se como um elemento importante na configuração e no desempenho dos sistemas nacionais de inovação (MELO, 1994). Nesse aspecto da relação entre financiamento da inovação e o sistema financeiro, destaca-se a tipologia formulada por Zysman (1983), baseada nas distintas formas de provisão de funding para o investimento das empresas. Na abordagem proposta, o autor identificou três tipos de arranjos institucionais: (i) sistemas baseados no mercado (market-based), caracterizados por um mercado de capitais altamente desenvolvido e com pouca influência do governo e; (ii) sistemas baseados no crédito (credit-based), com domínio das instituições financeiras, podendo ter um forte controle ou (iii) domínio das instituições financeiras, com baixa intervenção do governo.

A inovação é o resultado de um processo complexo e incerto emanado da aprendizagem interativa baseada na ciência e na experiência (LUNDVALL, 2008). Pela sua natureza, as análises, tanto de projetos quanto das estratégias de inovação, impõem dificuldades para as instituições financeiras, que não possuem conhecimentos técnicos-específicos. A inovação é fundamentalmente tácita e, portanto, de difícil transferência e fortemente específica ao seu contexto (MELO, 2009). Uma maneira de construir uma base de informações e aumentar a confiança nas empresas tomadoras seria através de seguidos contratos entre credores e devedores, o que propiciaria o aprendizado e o acúmulo de conhecimentos por parte da instituição financeira. Outra forma seria a criação de 
instituições financeiras especializadas para difundir o conhecimento gerado e dar suporte à criação de novos conhecimentos (CHRISTENSEN, 1992).

A empresa inovadora, para se manter competitiva, realiza investimentos em novos ativos e projetos. Para que isso ocorra, são necessários financiamentos em condições especiais, no que diz respeito às taxas de juros, aos prazos e ao volume financeiro. As instituições financeiras, com o passar do tempo, acumulam experiências nas análises das demandas das empresas, aperfeiçoando o processo de seleção dos projetos. Existe então uma influência das estruturas financeiras sobre a dinâmica de inovação das empresas, em relação à velocidade e à forma de acumular conhecimento (DOSI, 1990).

O processo de inovação envolve o aprendizado por parte da firma, caracterizado pelo seu caráter cumulativo (NELSON; WINTER, 1982). Esse aprendizado constitui uma dimensão relevante quando se discute os esforços tecnológicos desenvolvidos pelas empresas inovadoras. A base de conhecimento da empresa diz respeito não apenas ao nível do domínio do processo produtivo e das tecnologias relevantes, mas também das suas habilidades acumuladas e da sua capacidade de aprendizagem (NELSON, 1991). Essa aprendizagem consiste no processo das empresas acumularem capacidades tecnológicas ao longo do tempo (FIGUEIREDO, 2004).

Os primeiros estudos sobre capacidade tecnológica emergiram na América Latina, nos anos 1970. A partir de um programa de pesquisa liderado por Jorge Katz (1976), surgiu o entendimento de capacidade tecnológica como o esforço criativo sistemático para obter novos conhecimentos no nível da produção. Bell e Pavitt (1995) ampliaram a definição, concluindo que a eficiência da empresa não é afetada apenas pela aquisição de tecnologia externa, mas devem ser consideradas as capacidades tecnológicas necessárias para gerir e gerar mudanças internas nas tecnologias usadas na produção. Lall (1992) definiu a capacidade tecnológica como sendo um processo contínuo de absorção e criação de conhecimento tecnológico a partir da interação com o meio ambiente e do acúmulo de habilidades dominadas por uma empresa. Ou seja, o conhecimento e o aprendizado constituem-se fontes de criação de valor e de capacidade tecnológica para as empresas, sendo fundamentais para a compreensão dos processos de inovação.

A política macroeconômica tem importante função na melhor utilização dos mecanismos de apoio à inovação. As características dos sistemas macroeconômicos determinam e modelam as diversas decisões microeconômicas, dentre as quais o padrão de financiamento e as mudanças técnicas a serem implementadas (COUTINHO, 2002). Essa agenda de política macroeconômica nos países mais avançados tem procurado incorporar, em um mesmo nível de importância, estratégias de desenvolvimento industrial e de inovação, ao invés de focar apenas nos aspectos monetários, fiscais e cambiais.

Portanto, o Estado, por meio de suas instituições financeiras, é um ator-chave para o desenvolvimento das inovações do setor industrial. Os instrumentos de políticas desenhados para apoiar a inovação nem sempre alcançam a eficácia esperada, talvez pela falta de receptividade das próprias empresas, ou, ainda, pela ausência de articulação com outras políticas que são implementadas. Nesse contexto, um olhar sobre o financiamento da inovação à luz dos seus efeitos de criar e de acelerar o processo de acumulação das capacidades tecnológicas das empresas farmacêuticas apoiadas com recursos públicos torna-se necessário, em um contexto de avaliação de política de inovação.

\section{Metodologia da análise: o financiamento com crédito e o esforço de inovação}

A metodologia do artigo está baseada no estudo de caso da evolução da indústria farmacêutica brasileira, fundamentada em fontes secundárias de informação e avaliadas de maneira qualitativa. Para analisar os efeitos dos financiamentos dos projetos de inovação nessa indústria, foram utilizadas as bases de dados dos contratos diretos do BNDES e da Finep, obtidas nos sites das duas instituições, na seção intitulada Transparência. Os projetos foram organizados por ano de contratação, porte das empresas, objetivos, valor contratado, valor desembolsado, dentre outras características. O período considerado são os anos de 2006 a 2018. Esses anos são convenientes para a avaliação, pois marcam a execução de políticas industriais e de inovação no Brasil e cobrem a sua descontinuidade. Além disso, esse espaço de tempo cobre os ciclos da pesquisa de inovação (Pintec), permitindo analisar, de maneira integrada, se o apoio público para inovação resultou no aumento das capacitações tecnológicas das empresas e, consequentemente, elevou o nível de competitividade das empresas desse setor.

Para uma análise do desembolso total para inovação de todos os setores da economia, foi utilizada, no caso do BNDES, a classificação disponibilizada de quais projetos eram para esse fim e, então, construída uma lista daqueles que foram contratados, considerando os desembolsos ocorridos. O mesmo processo foi feito para a Finep, no entanto levou-se em conta todos os financiamentos dessa agência, tendo em vista o seu apoio estar concentrado necessariamente em projetos de inovação.

Para o caso dos projetos financiados pelo BNDES no âmbito da indústria farmacêutica, foi necessário realizar algumas adequações específicas para atender aos objetivos da pesquisa. Foram selecionadas as seguintes modalidades operacionais: BNDES Financiamento a empresa direto, BNDES Compra de máquinas e equipamentos direto e BNDES Importação de bens/serviços direto. Essas modalidades fizeram parte do Programa que apoiou a indústria 
farmacêutica, o Profarma, lançado em abril de 2004 e descontinuado em 2017. Alguns dos projetos selecionados continham subcréditos; nesse sentido, optou-se por somar todos esses valores e considerar um único projeto de financiamento. Para os projetos da Finep, não foi preciso fazer nenhum tratamento específico, apenas incorporar as empresas na base e ajustá-las nos mesmos padrões.

Após as adequações, foi formada uma base única para o segmento farmacêutico. O resultado é uma lista de empresas do setor que realizaram desenvolvimentos de produtos ou processos inovadores, cujos projetos foram financiados com créditos subsidiados do BNDES e da Finep.

Em relação às liberações dos recursos, em alguns dos projetos, o cronograma é de fato o que aconteceu ou ainda irá acontecer. Entretanto, em outros casos, foi necessário estimar as datas de desembolso para realizar as análises neste artigo, considerando parcelas anuais, a partir do momento da contratação. Para essas situações, foram adotadas as seguintes regras:

- Valor do financiamento maior do que $\mathrm{R} \$ 15$ milhões, $1^{\mathrm{a}}$ parcela, $40 \%$ do valor do contrato; $2^{\mathrm{a}}$ parcela, $30 \%$ do valor do contato e $3^{\mathrm{a}}$ parcela, $30 \%$ do valor do contrato;

- Valor do financiamento entre R 55 milhões e R $\$ 15$ milhões, $1^{\text {a }}$ parcela, 50\% e $2^{\mathrm{a}}$ parcela, 50\%;

- Valor do financiamento menor do que R 5 milhões, 1(uma) liberação.

Na sequência, após a organização das liberações, os projetos foram classificados por plataforma tecnológica. Essa classificação foi feita com base nos objetivos de cada um dos projetos e separadas em síntese química ou biotecnologia ${ }^{5}$. Uma vez que essas duas plataformas possuem naturezas distintas, um olhar sobre os projetos nessa perspectiva contribuirá para verificar os esforços de inovação do setor.

Outra classificação realizada por meio dos objetivos dos projetos foi identificar onde seriam investidos, principalmente, os recursos do financiamento. Assim, os projetos foram também classificados por atividades de inovação principal. Essa classificação consistiu em: Biotecnologia (biofármacos, insulinas, vacinas); Desenvolvimento de Fitoterápicos; Desenvolvimento de Insumo farmacêutico Ativo (IFA); Expansão do portfólio de produtos (similares e genéricos); Fusão e Aquisição; Modernização da Planta (produção, máquinas e equipamentos, centro de distribuição, embalagens) e; Preparações farmacêuticas. A organização dos projetos por área de conhecimento permitiu uma análise qualitativa dos esforços e da trajetória de inovação das empresas farmacêuticas financiadas, possibilitando verificar o impacto do financiamento sobre o aumento das capacidades tecnológicas.

O estudo envolveu ainda o uso dos dados da Pesquisa de Inovação Brasileira, a qual adota metodologias consolidadas internacionalmente pelo Manual de Oslo, elaborado sob a responsabilidade da Organização para a Cooperação e Desenvolvimento Econômico (OCDE, 2018). Para que fossem verificados os esforços de inovação do setor, foram utilizadas as últimas quatro edições, de 2008 a 2017. Nesse caso o código da Classificação Nacional de Atividades Econômicas (CNAE 2.0) disponível para trabalhar foi o 21 Fabricação de produtos farmoquímicos e farmacêuticos. Além disso, foi utilizada uma tabulação especial, produzida pelo IBGE, contendo um conjunto de estatísticas do tipo somatória para o recorte amostral das empresas farmacêuticas financiadas pelo BNDES e pela Finep. Analisar as alterações ocorridas nessas empresas ajuda a entender se as capacidades técnicas foram incorporadas, após o apoio público.

Cabe destacar ainda que foram descontados os efeitos da inflação, utilizando-se como deflator o IGP-DI da Fundação Getúlio Vargas, para o mês de dezembro do ano-base de 2019.

Por fim, considera-se que, apesar das limitações e possíveis vieses desse tipo de abordagem metodológica, a avaliação sobre o desempenho do setor farmacêutico, com base nos dados de financiamento do BNDES e da Finep, fornece informações relevantes sobre o impacto do apoio público na construção de capacidades tecnológicas, que podem ser de interesse para os formuladores de políticas.

\section{Resultados do apoio à inovação do BNDES e da Finep}

O BNDES e a Finep possuem um portfólio diversificado de instrumentos financeiros para apoiar a inovação. O crédito com taxas subsidiadas é o de maior prevalência, tanto em termos de volume financeiro quanto em quantidades de operações. Ao financiar os projetos, essas duas instituições de fomento levam em conta não apenas os aspectos da inovação, mas também os efeitos de transbordamento tecnológico para o restante da cadeia produtiva. Outro papel que eles assumem é o de considerar algum tipo de retorno social, pois bancos privados tendem a ignorar também essa variável (STIGLITZ; JARAMILLO-VALLEJO; PARK, 1993).

$\mathrm{O}$ instrumento de crédito com taxas subsidiadas é o principal mecanismo de estímulo às atividades de inovação utilizado no Brasil, além dos incentivos fiscais (BRASIL, 2019). As empresas brasileiras enfrentam

\footnotetext{
5 A definição utilizada para produtos biotecnológicos é a de medicamentos para uso humano de origem biológica, isto é, hemoderivados, vacinas ou biofármacos (RDC Anvisa no 55 de 16 de dezembro de 2010 - Anexo).
} 
diferentes restrições para inovar, com destaque para os elevados custos financeiros (IBGE, 2017). A falta de acesso ao crédito é uma dessas restrições e pode impedi-las de executarem seus projetos de inovação. Tal situação faz com que aquelas de grande porte dependam de suas próprias fontes para financiar os investimentos. Por outro lado, os projetos das pequenas e médias podem não acontecer e, assim, esses tipos de empresas irão ver os seus negócios estagnarem ou serem interrompidos.

O Gráfico 1 apresenta os desembolsos do BNDES e da Finep para os projetos de inovação de todos os setores da economia e para as empresas farmacêuticas, entre os anos de 2006 e 2018. Percebe-se um período de aceleração das liberações dos recursos, com o ano de 2014 destacando-se pelo maior volume financeiro alocado, enquanto, na sequência, ocorre uma redução acelerada, resultando, ao final da série analisada, valores de desembolsos próximos aos níveis dos anos de 2008 e 2009.

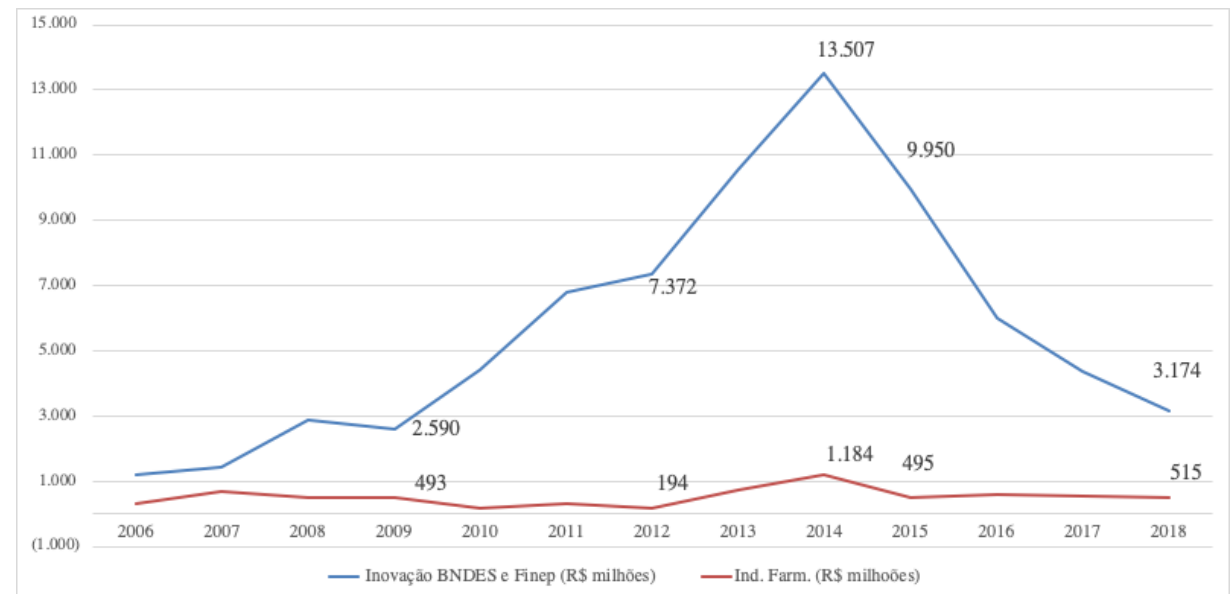

Gráfico 1 - Desembolso total para inovação e desembolso para as empresas farmacêuticas do BNDES e da Finep (2006 até 2018) - R\$ milhões

Fonte: Elaboração própria, com base em dados do BNDES e da Finep

Deflator IGP - DI (dez/2019).

A partir de 2007, houve um forte crescimento dos recursos para as atividades de inovação. A retomada das políticas industriais no país explica essa trajetória, pois procuraram estimular alguns setores a adotar estratégias de diferenciação de produtos e processos. Nesse período, também, o Estado passou a adotar um papel mais ativo, por meio do Programa de Sustentação do Investimento (PSI), criado pelo Governo Federal em 2009. O objetivo desse programa era financiar a compra de máquinas e equipamentos produzidos no país, permitindo investimentos em inovação. O PSI, como funding, reuniu, ao mesmo tempo, as funções de política de investimentos anticíclica, mitigando os efeitos negativos da crise financeira internacional de 2008, explicitou prioridades da política industrial e concedeu subsídios creditícios à inovação com equalização da taxa de juros e oferta de crédito com taxas nominais abaixo da inflação (ARAÚJO, 2012).

Em relação à indústria farmacêutica, o desembolso chegou a R \$ 1.184 milhões em 2014, representando 9\% do total desembolsado para projetos de inovação (Gráfico 1). No ano de 2009, essa proporção alcançou $19 \%$ dos investimentos totais, com R $\$ 493$ milhões; já no ano de 2018, esse montante foi de R \$ 515 milhões, significando $16 \%$ dos desembolsos somados. Nota-se, portanto, que o setor farmacêutico ocupou um espaço relevante nas ações das duas instituições, com volumes financeiros representativos para o desenvolvimento de produtos e processos inovadores.

Alguns programas específicos para o setor farmacêutico foram implementados pelo BNDES e pela Finep e contribuíram para a participação do desembolso apresentado. O principal deles foi o Profarma ${ }^{6}$, cuja primeira fase foi lançada em 2004 pelo BNDES. O objetivo dessa ação era contribuir para a redução da vulnerabilidade da Política Nacional de Saúde e promover a articulação entre as políticas industrial e de saúde. O foco era financiar os investimentos de capital e de inovação. Ao longo desse período, desde o ano de 2004, a Finep atuou sem um programa estruturado para a indústria farmacêutica, financiando projetos de acordo com a demanda, exceto em 2013, quando

${ }^{6}$ O Profarma foi o Programa de Apoio à Cadeia Farmacêutica, lançado em abril de 2004, no contexto da Política Industrial, Tecnológica e de Comércio Exterior (PITCE) e descontinuado em 2017. Em sua primeira fase, dispunha de três propostas de ação, caracterizadas em torno de três subprogramas específicos: produção, fortalecimento das empresas nacionais e P,D\&I. Em 2007, o BNDES anunciou a segunda fase do Profarma, com cinco subprogramas: produção, exportação, inovação, reestruturação e produtores públicos. Em 2013, o BNDES renovou, mais uma vez, o programa, incorporando a biotecnologia como um dos objetivos. 
foi lançado o Programa Inova Saúde ${ }^{7}$ Nesse mesmo ano, foi implementada, também, a terceira fase do Profarma, com foco em ações no segmento de biotecnologia.

As empresas farmacêuticas apoiadas pelas duas instituições entre os anos de 2006 e 2018 foram, majoritariamente, as de grande porte (49\%); $27 \%$ eram médias e $24 \%$ corresponderam a pequenas empresas. A rentabilidade dessas empresas, medida de forma ampla pelo quociente da receita total e do custo total, foi de $15 \%$, em média, entre os anos de 2007 e 2018 (IBGE, 2018). Esse desempenho é bastante superior ao da indústria de transformação, que foi de $5 \%$, em média, considerando os mesmos anos.

Em relação ao número de projetos, esse período indicou o apoio a 113 projetos de inovação, sendo, em sua maioria, iniciativas relacionadas ao desenvolvimento de produtos de origem química (84\%). O restante foram projetos que envolviam inovações em biotecnologia (16\%). As barras do Gráfico 2 apresentam os valores dos contratos dos projetos de inovação para a indústria farmacêutica, por ano de contratação, os quais somados totalizaram $\mathrm{R} \$ 9,2$ bilhões. A linha contínua indica os recursos desembolsados, conforme o ano em que as empresas acessaram as liberações. Nesse caso, somando todos os anos, os valores alcançaram R \$ 6,9 bilhões.

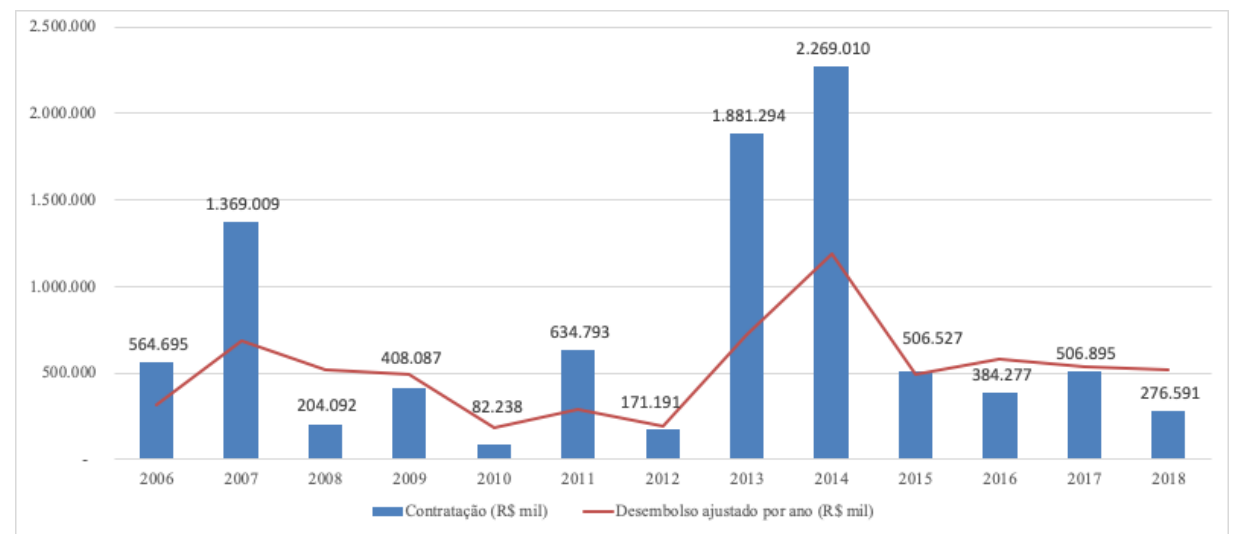

Gráfico 2 - Dispêndios em Inovação - Contratação e Desembolso para Indústria Farmacêutica (2006 até 2018) - R\$ mil

Fonte: Elaboração própria, com base em dados do BNDES e da Finep Deflator IGP - DI (dez/2019).

Outra característica dos financiamentos concedidos pelo BNDES e pela Finep para a indústria farmacêutica foi o número reduzido de empresas que receberam o apoio. O Quadro 1 enumera as 10 principais empresas que obtiveram recursos para executar os seus respectivos projetos de inovação, entre os anos de 2006 e 2018. Em valores corrigidos, esses contratos representam $82 \%$ do total financiado e $48 \%$ em número de projetos, considerando os anos analisados. Essa situação comprova uma persistente concentração do apoio em poucas empresas.

De acordo com a pesquisa de inovação do ano de 2017 (IBGE, 2017), ao compararmos o faturamento das empresas farmacêuticas financiadas pelo BNDES e pela Finep com o total das receitas líquidas de venda (RLV) do setor farmacêutico foi possível perceber que as empresas que receberam o suporte financeiro público detinham quase $40 \%$ da RLV total do setor. Nesse contexto, o pequeno grupo de empresas farmacêuticas financiadas são aquelas que possuem um maior market share.

\footnotetext{
${ }^{7}$ O Inova Saúde foi lançado no âmbito do Plano Inova Empresa. O objetivo era apoiar projetos de P,D\&I em fármacos obtidos por processos de síntese química, biotecnológicos e extrativos, para desenvolvimento de medicamentos, novos ou genéricos, em atendimento às demandas do SUS.

${ }^{8} \mathrm{Nem}$ todos os projetos são desembolsados integralmente, ou seja, o valor total do contrato. Os motivos para interrupção envolvem normalmente questões técnicas, como, por exemplo, insucesso do processo de inovação, questões financeiras, como garantias para parcela subsequente, ou ainda, problemas jurídicos, como a falta de alguma certidão necessária.
} 


\begin{tabular}{|c|l|r|r|}
\hline \multicolumn{1}{|c|}{ Empresas } & \multicolumn{1}{|c|}{$\begin{array}{c}\text { Valor do contrato do } \\
\text { financiamento (R\$) }\end{array}$} & $\begin{array}{c}\text { Número de } \\
\text { projetos }\end{array}$ \\
\hline 1 & ACHE LABORATORIOS FARMACEUTICOS SA & 1630441551 & 11 \\
\hline 2 & EMS S/A & 1484358982 & 12 \\
\hline 3 & LIBBS FARMACEUTICA LTDA & 1148760898 & 5 \\
\hline 4 & EUROFARMA LABORATORIOS S.A. & 772202774 & 9 \\
\hline 5 & HYPERA S/A & 591215239 & 3 \\
\hline 6 & ORYGEN BIOTECNOLOGIA S.A. & 476503472 & 2 \\
\hline 7 & BIONOVIS S.A. & 494071862 & 2 \\
\hline 8 & PRATI, DONADUZZI \& CIA LTDA & 408090771 & 6 \\
\hline 9 & BIOLAB SANUS FARMACEUTICA LTDA & 289042889 & 3 \\
\hline 10 & NOVARTIS BIOCIENCIAS S/A & 253094252 & 1 \\
\hline \multicolumn{2}{|r|}{ TOTAL } & $\mathbf{7 5 4 7 7 8 2 6 9 1}$ & $\mathbf{5 4}$ \\
\hline
\end{tabular}

Quadro 1 - Principais empresas farmacêuticas apoiadas com o instrumento de crédito do BNDES e da Finep entre os anos de 2006 e 2018

Fonte: Elaboração própria, com base em dados do BNDES e da Finep. Deflator IGP - DI (dez/2019).

Quando uma empresa decide financiar os seus investimentos em inovação, este crédito, de alguma forma, acaba contribuindo para elevar o grau de suas competências em um primeiro momento e, consequentemente, pode estimular um efeito de segunda ordem caracterizado pelo acúmulo de novas capacidades tecnológicas e pelo aumento das receitas de inovação. Os recursos do BNDES e da Finep podem gerar um resultado direto sobre os esforços de inovação nas empresas apoiadas, seja viabilizando um novo projeto seja complementando os recursos que elas já estariam dispostas a investir.

A fim de identificar quais seriam as características principais dos financiamentos e quais as capacidades tecnológicas essas empresas estariam buscando adquirir, foram criados alguns indexadores a partir dos objetivos de cada um dos projetos. No Gráfico 3, procura-se ilustrar o destino dos recursos de inovação, baseando-se no valor do contrato de cada projeto, corrigido por um índice de inflação. De certa forma, as iniciativas das empresas estiveram mais focadas, em sua maioria, nas atividades de menor risco tecnológico e de formação de uma base produtiva nacional. Por outro lado, a partir de 2013, com o uso combinado dos instrumentos de políticas, foi possível verificar o início dos projetos estruturantes em biotecnologia.

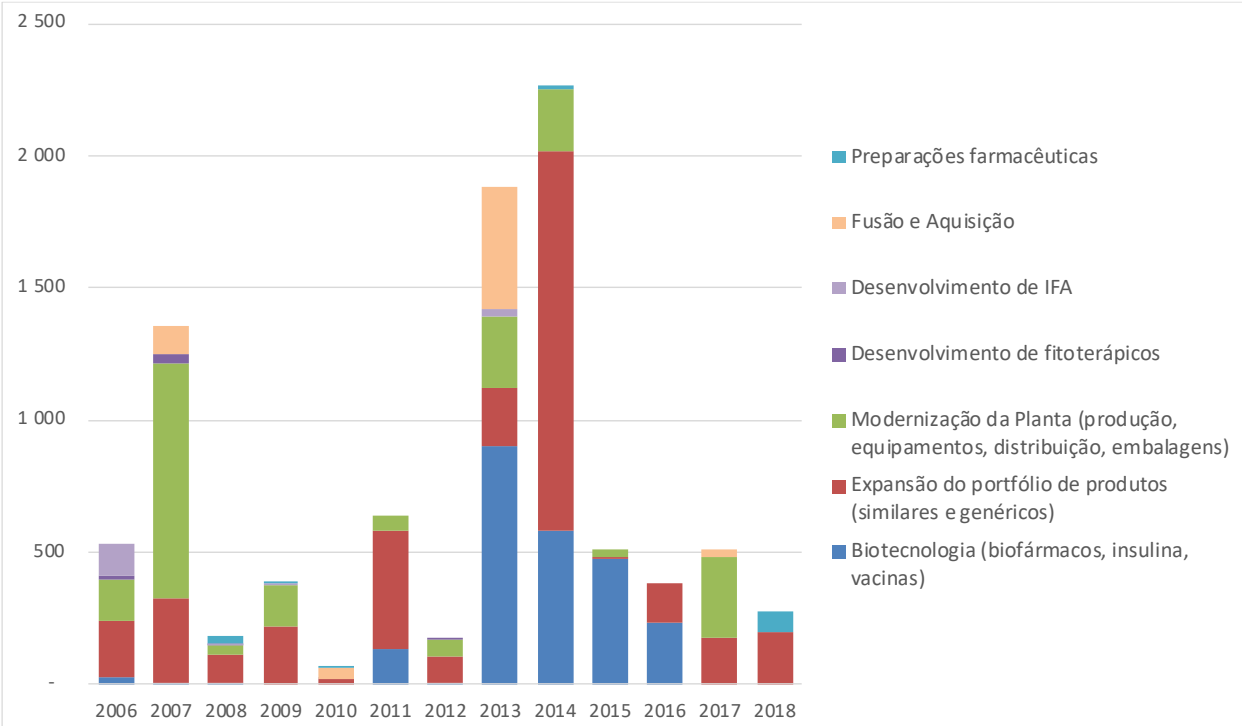

Gráfico 3 - Investimentos realizados com o financiamento do BNDES e da Finep (2006 até 2018)

- valores do contrato ( $\mathrm{R} \$$ milhões)

Fonte: Elaboração própria, com base em dados do BNDES e da Finep.

Deflator IGP - DI (dez/2019).

A expansão do portfólio de produtos foi a finalidade que recebeu a maior parte dos recursos de financiamento. Nele, estão contidos os desenvolvimentos de medicamentos novos, mas principalmente medicamentos genéricos e similares. Esses projetos representaram 39\% dos recursos investidos em inovação, por meio do financiamento. Os produtos genéricos e similares ainda se mostram importantes direcionadores das estratégias das empresas no Brasil. 
As receitas de vendas desses medicamentos corresponderam a $\mathrm{R} \$ 23,5$ bilhões, no ano de 2018, 35\% do mercado farmacêutico brasileiro (INTERFARMA, 2019; ANVISA, 2019).

O financiamento do investimento em ativos tangíveis para a modernização inclui, também, uma proporção de investimento intangível, incorporado nas máquinas e equipamentos adquiridos (MELO, 1994). Uma parte dos projetos financiados está concentrada nessas inovações incorporadas por meio de atualizações tecnológicas, representando $24 \%$ dos recursos de inovação. Esses projetos envolvem pouca incerteza e baixo risco tecnológico e estão voltados principalmente em aumentar ou preparar o ambiente de produção.

Os projetos de biotecnologia são aqueles que exigem as maiores capacitações e esforços de inovação, com destaque para o domínio das técnicas que desenvolvam os medicamentos de origem biológica. Foram alocados cerca de $\mathrm{R} \$ 2,3$ bilhões em projetos dessa área, o que representa 26\% do total investido. O BNDES e a Finep apoiaram as empresas a ingressarem no desenvolvimento dos biofármacos, criando programas específicos e utilizando condições financeiras diferenciadas. Esses medicamentos estão na fronteira do conhecimento e são de alto valor agregado, tendo correspondido a 37\% do orçamento da Assistência Farmacêutica do Ministério da Saúde, em 2018 (INTERFARMA, 2019).

Algumas empresas farmacêuticas nacionais buscaram o financiamento como forma de viabilizar estratégias de fusões e aquisições. O objetivo dessa iniciativa foi adquirir novos conhecimentos e ativos tecnológicos no exterior. Três exemplos ilustram essa prática: a aquisição do laboratório argentino Quesada Farmacêutica pela empresa Eurofarma, no valor R \$ 42 milhões em 2010, a aquisição da empresa Nortis pela empresa Aché, no valor de R\$ 22 milhões em 2017, e o caso da empresa nacional EMS, que criou uma subsidiária nos Estados Unidos, Brace Pharma, para atuar no investimento em aquisições de parte das companhias que desenvolvem moléculas promissoras, no valor de $\mathrm{R} \$ 463$ milhões em 2013.

As demais atividades para as quais foram destinados os recursos de inovação - preparações farmacêuticas, desenvolvimento de insumo farmacêutico ativo e desenvolvimento de fitoterápicos - não tiveram valores expressivos de projetos contratados. Entre os anos de 2006 e 2018, foram financiados cerca de R \$ 357 milhões do total para essa finalidade.

Em síntese, os financiamentos estiveram concentrados nas grandes empresas farmacêuticas de capital nacional, sendo elas as mais sólidas do ponto de vista econômico-financeiro e de participação das vendas no mercado. Percebe-se uma predominância do financiamento em atividades de inovação de menor incerteza, caracterizadas por modernização e expansão da produção, além do desenvolvimento de genéricos e similares. É importante medir os esforços de inovação do setor, por meio dos gastos em pesquisa e desenvolvimento. A partir dessa análise, será possível concluir se os investimentos realizados tiveram alguma consequência na aquisição de competências e habilidades pelas empresas farmacêuticas que receberam o apoio do BNDES e da Finep.

\section{A capacitação para inovação das empresas farmacêuticas}

\subsection{Uma análise dos principais indicadores de inovação do setor}

O objetivo desta subseção é analisar a trajetória das empresas do setor farmacêutico como um todo no que diz respeito aos esforços de inovação, com base em alguns indicadores selecionados. Os aspectos referentes à dinâmica do setor explicitam a necessidade de associar o fortalecimento da estrutura produtiva com estratégias ativas de inovação. Tal situação mostra que o acesso aos novos conhecimentos, derivados das políticas de inovação implementadas nos últimos anos, permitiram identificar algumas mudanças nesse tipo de atividade por parte dessas empresas.

As empresas do setor farmacêutico brasileiro apresentaram uma rentabilidade 9 econômico-financeira significativa. Por outro lado, ainda há uma condição de vulnerabilidade externa (VARGAS; ALMEIDA; GUIMARÃES, 2017; GADELHA; TEMPORÃO, 2018) decorrente do crescente volume de importações ${ }^{10}$. Para suportar essa situação são necessárias estruturas de grandes empresas, as quais as eficiências produtivas e comerciais estão presentes. Alguns movimentos puderam ser observados ao longo dos últimos anos, tais quais processos de fusões e aquisições ou interrupção da produção em algumas plantas, seja por questões estratégicas seja por problemas financeiros. O que se nota por meio da Pintec do ano de 2017 é a redução expressiva do número de empresas que implementaram inovações, passando de $315 \mathrm{em} 2008$ para 177 (Tabela 1) (IBGE, 2017).

\footnotetext{
${ }^{9}$ A rentabilidade do setor farmacêutico (CNAE 21.21) foi em média 10\%, enquanto a da indústria de transformação foi de 5\%, entre os anos de 2007 e 2018 (IBGE, 2018).

${ }^{10}$ Cerca de $70 \%$ do déficit está relacionado com a importação de medicamentos acabados e, em menor escala de farmoquímicos. A balança comercial de produtos farmacêuticos (NCM 30) apresentou um déficit de US\$ 5,8 bilhões no ano de 2018 (COMEXSTAT, 2020).
} 
Tabela 1 - Número de empresas inovadoras e Taxa de Inovação das empresas farmacêuticas

\begin{tabular}{|c|c|c|c|c|}
\hline Variáveis e Indicadores & 2008 & 2011 & 2014 & 2017 \\
\hline Número de empresas & 315 & 247 & 212 & 177 \\
\hline Taxa de Inovação & $63,7 \%$ & $53,8 \%$ & $52,2 \%$ & $40,6 \%$ \\
\hline
\end{tabular}

Fonte: Elaboração própria, com base em dados do IBGE (2017).

A taxa de inovação é um indicador importante. Ela pode ser calculada pelo número de empresas que realizaram inovações em relação ao total das empresas pesquisadas do setor. A Tabela 1 revela que a taxa de inovação da indústria farmacêutica (CNAE 21) entre 2008 e 2017 diminuiu consideravelmente, deslocando-se de 63,7\% para 40,6\%. A redução do número de empresas que implementaram inovações, somadas ao desempenho da taxa de inovação, permite concluir que essas atividades passaram a se concentrar em poucas empresas.

A intensidade de $\mathrm{P} \& \mathrm{D}^{11}$ é outro indicador relevante para ser observado, pois permite comparar o desempenho das farmacêuticas brasileiras com as grandes empresas globais, as chamadas big pharmas. Enquanto os maiores grupos empresariais do mundo investem em média $20 \%$ da RLV em P\&D ${ }^{12}$, as empresas do Brasil investem 4,4\%, em média, conforme as últimas edições da pesquisa de inovação. Esse indicador, portanto, para as empresas farmacêuticas brasileiras, segue trajetória decrescente, passando de 4,9\% em 2008 para 3,6\% em 2017, conforme apresentado na Tabela 2 .

Tabela 2 - Dados da Pintec (valores nominais) e Intensidade de P\&D das empresas farmacêuticas - anos da Pintec

\begin{tabular}{|c|c|c|c|c|}
\hline Variáveis e Indicadores & 2008 & 2011 & 2014 & 2017 \\
\hline $\begin{array}{c}\text { Dispêndios em Atividades } \\
\text { de Inovação (R\$ bilhões) }\end{array}$ & 2,7 & 2,9 & 3,0 & 2,5 \\
\hline RLV (R\$ bilhões) & 55,2 & 60,9 & 73,1 & 70,3 \\
\hline Intensidade de P\&D & $4,9 \%$ & $4,8 \%$ & $4,2 \%$ & $3,6 \%$ \\
\hline
\end{tabular}

Fonte: Elaboração própria com base em dados do IBGE (2017).

Deflator IGP - DI (dez/2019).

Além de mostrar a distância que as empresas brasileiras estão, em termos de gastos com as atividades de inovação, a intensidade de P\&D revela a diferença existente entre o desempenho dos dispêndios nessas atividades e a RLV ao longo dos últimos anos. Conforme destacado na Tabela 2, a variação dos investimentos em atividades de inovação expressou um crescimento médio ponderado de $-1 \%$ entre os anos de 2008 e 2017, movendo-se de $\mathrm{R} \$ 2,7$ bilhões para R \$ 2,5 bilhões. Por outro lado, a RLV apresentou um crescimento, também médio ponderado, de 6\%, no mesmo período, de $\mathrm{R} \$ 55,2$ bilhões para $\mathrm{R} \$ 70,3$ bilhões. A constatação é de que o montante direcionado para as atividades de inovação foram insuficientes para manter o indicador intensidade de P\&D no patamar próximo de 5\%, por exemplo, observado na pesquisa de 2008.

Para atingir ao nível de 5\% do indicador intensidade de P\&D, seria necessário ampliar em R \$ 962 milhões os investimentos, mantida a RLV constante, em valores reais de 2017. Esse volume financeiro representa um aumento para o setor, traduzido em 37,6\% dos dispêndios em atividades de inovação. Como comparação, as empresas farmacêuticas financiadas pelo BNDES e pela Finep receberam em novos contratos, em média, R \$ 712,2 milhões por ano, novamente em valores reais, para financiar os seus projetos de inovação, entre os anos de 2006 e 2018.

É importante considerar a influência da conjuntura econômica do Brasil sobre os esforços de inovação da indústria. A pesquisa de 2017 reflete, de forma significativa, o período de recessão que o país enfrentou em 2015 e 2016. Ao analisar alguns indicadores da indústria de transformação, é possível confrontá-los com o desempenho do

\footnotetext{
${ }^{11}$ Intensidade de P\&D é o indicador que representa os dispêndios em atividades de P\&D dividido pelas receitas líquidas de vendas das empresas que realizaram P\&D (NATIONAL SCIENCE BOARD, 2020).

12 As 10 maiores empresas farmacêuticas mundiais investiram, em atividades de P\&D, US\$ 68,8 bilhões, em 2018. Elas concentram cerca de $40 \%$ de todos os investimentos em P\&D do setor, que investiu US\$178 bilhões, em 2018. Isto representa, em média, 20\% de investimento em P\&D sobre a RLV desse grupo de empresas (WATERS; URQUHART, 2019).
} 
setor farmacêutico. A RLV da indústria de transformação apresentou um crescimento médio ponderado de $13 \%$ e uma taxa de inovação que diminuiu quatro pontos percentuais, de $38 \%$ para $34 \%$, quando se olha para as pesquisas de 2008 a 2017. Além disso, o indicador intensidade de P\&D alcançou 1,6\% na pesquisa de 2017 e os gastos de P\&D aumentaram, em média ponderada, 1,7\%, de 2008 a 2017. Em síntese, os dados permitem identificar que houve uma queda generalizada nos esforços de inovação da indústria brasileira entre 2014 e 2017, apresentando resultados adversos tanto na indústria de transformação quanto na indústria farmacêutica.

Nota-se, portanto, que a realidade do setor farmacêutico brasileiro continua distante das dinâmicas financeira e de inovação adotadas pelas grandes empresas globais desse segmento. O crescimento expressivo das RLV das empresas brasileiras significa a existência de um setor robusto do ponto de vista econômico e que tem investido em inovação em patamares acima da média nacional ${ }^{13}$, mas ainda insuficiente para ser competitiva. Apesar das crises política e econômica pelas quais o país atravessou, nos anos de 2015 e 2016, uma parte dessas empresas enfrentou o período sem muitas turbulências, com desempenho dos indicadores de inovação superior ao apresentado pela indústria de transformação. É importante entender o papel do apoio público, por meio do financiamento do BNDES e da Finep, a fim de verificar se foram criadas capacidades para inovação nessas empresas.

\section{2. $O$ apoio do BNDES e da Finep na tentativa de ampliar os esforços de inovação}

Nas duas primeiras décadas do século XXI, algumas políticas industriais e de inovação foram implementadas para estimular a indústria farmacêutica brasileira. Instrumentos de políticas, sobretudo o crédito subsidiado, foram utilizados na tentativa de ampliar os esforços de inovação do setor. O objetivo desta subseção é analisar os efeitos dos financiamentos do BNDES e da Finep sobre a criação de novas capacidades tecnológicas nas empresas farmacêuticas que receberam esses recursos, a partir de alguns indicadores.

Ao comparar as empresas do setor (CNAE 21) e aquelas que receberam financiamento do BNDES e da Finep para aquisição de máquinas e equipamentos, é possível identificar padrões diferenciados de esforços de inovação nesse aspecto (Gráfico 4). Na Pintec de 2008 (IBGE, 2017), 64\% das empresas farmacêuticas que implementaram inovações obtiveram recursos do governo e utilizaram o financiamento para compra de máquinas e equipamentos para inovar. Em 2017, para esse mesmo fim, a proporção passou para 11\% das empresas. Por outro lado, ao olhar somente para as empresas farmacêuticas financiadas pelas duas instituições de fomento, nota-se que esse indicador não oscilou significativamente, ficando, em média, $26 \%$ entre os anos de 2008 e 2017. Os investimentos em máquinas e equipamentos podem aumentar a capacidade produtiva das empresas, mas não necessariamente o nível de inovação tecnológica (RIBEIRO; DE NEGRI, 2009).

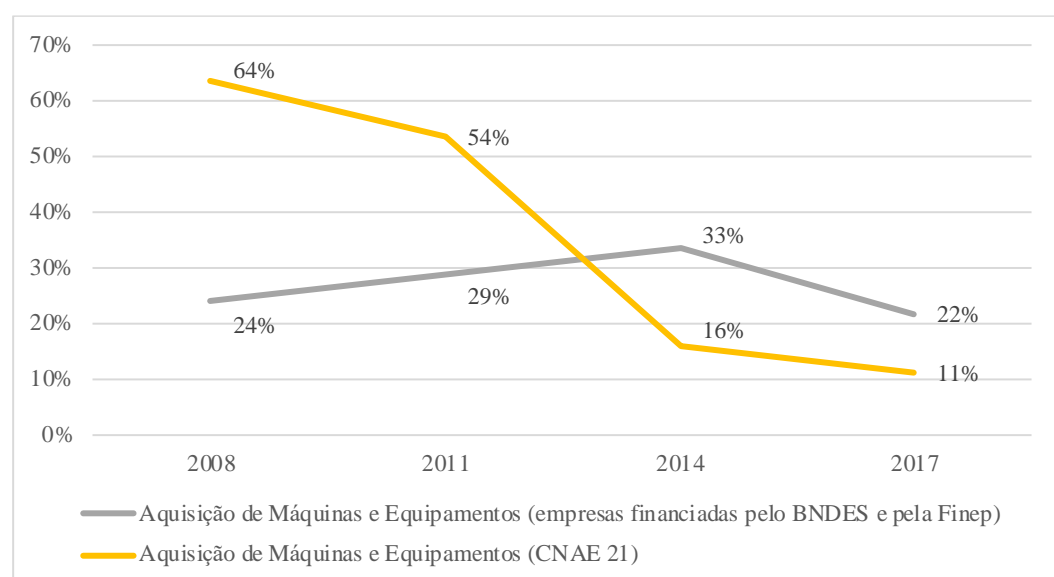

Gráfico 4 - Empresas farmacêuticas que receberam apoio do governo para aquisição de máquinas e equipamentos Fonte: Elaboração própria, com base em dados do IBGE (2017).

Os esforços em P\&D e inovação estão diretamente associados à capacitação tecnológica e representam um importante indicador do potencial inovador (TIGRE; NASCIMENTO; COSTA, 2016). Quanto maior a intensidade das atividades internas de P\&D, maior é a capacidade das empresas de identificar, assimilar e explorar o conhecimento existente em seu ambiente (COHEN; LEVINTHAL, 1990). As empresas farmacêuticas financiadas pelo BNDES e pela Finep ampliaram, de fato, os seus investimentos em inovação. Essas empresas apresentaram um crescimento de $85 \%$, em valores nominais, nas despesas com essas atividades, entre a pesquisa de 2008 e a de 2017

\footnotetext{
${ }^{13}$ A pesquisa estimou que, de um universo de 116.962 empresas com 10 ou mais pessoas ocupadas, aproximadamente $1 / 3$ foram inovadoras em produto ou processo, perfazendo uma taxa geral de inovação de 33,6\% no período 2015-2017 (IBGE, 2017).
} 
(IBGE, 2017). Ações nessa direção têm como objetivo expandir o estoque de conhecimento científico e tecnológico, a fim de aplicá-lo na produção de novos medicamentos. Entretanto, o que se viu foi a maior parte dos recursos concentrada na produção de medicamentos genéricos e similares, em ampliar a capacidade produtiva e modernizar as fábricas. Embora sejam ações necessárias, são insuficientes para acelerar o processo de aprendizagem tecnológica e aumentar o padrão de competitividade dessas empresas.

Além do crédito com taxas de juros subsidiadas, o incentivo fiscal é outro importante mecanismo para estimular os investimentos em pesquisa, desenvolvimento e inovação no Brasil. Alguns estudos (HALL; VAN REENEN, 2000; FREITAS et al., 2017; COLOMBO, 2017) fizeram o debate sobre a capacidade dos créditos tributários gerarem ou não efeitos de adicionalidade, contribuindo para impulsionar a inovação nas empresas. Nesse tipo de instrumento de política, as empresas envolvidas em atividades de P\&D podem solicitar reduções diretas no valor do imposto a ser pago e, dessa forma, reduzir os custos dos seus projetos existentes nessa atividade ou expandir sua escala (APPELT; GALINDO-RUEDA; GONZÁLES, 2019). Os formuladores de políticas, em geral, costumam ser simpáticos a essa modalidade, dentre outros motivos, por ela não priorizar setores e não incorrer em custos diretos para as empresas. Por outro lado, a dedução do imposto proporcional ao nível da despesa pode ter impacto limitado no tamanho dos investimentos em $\mathrm{P} \& \mathrm{D}$, podendo esse tipo de benefício ser mais propenso a gerar algum nível de crowding out.

As empresas farmacêuticas financiadas pelo BNDES e pela Finep também fizeram uso do incentivo fiscal para apoiar suas atividades de inovação, conforme os dados apresentados pela Pintec (IBGE, 2017). Em 2008, daquelas empresas financiadas, 57\% recorreram aos créditos tributários para inovação. Nas pesquisas de 2014 e 2017, olhando a mesma amostra, $96 \%$ delas acessaram essa modalidade. Além desse mecanismo ter se tornado quase uma unanimidade no que diz respeito ao acesso, percebe-se a tendência do elevado suporte público para apoiar as estratégias de inovação das empresas, combinando os instrumentos de política, crédito e incentivo fiscal.

O manual de Oslo (OCDE, 2018) e a Pintec (IBGE, 2017) definem inovação como sendo algo novo para a empresa que adota, não exigindo, necessariamente, que seja uma novidade para o mercado nacional ou internacional. Essa definição é bastante ampla e, ao aplicar para os projetos apoiados pelo BNDES e pela Finep, nota-se que as empresas farmacêuticas brasileiras costumaram aprimorar produtos e processos já existentes, incorporando tecnologias que são novas apenas para elas. A especialização no desenvolvimento de medicamentos genéricos e similares é um exemplo dessa estratégia, pois geraram, predominantemente, inovações incrementais no âmbito da firma ao invés de inovações para o mercado.

A pesquisa de 2014 mostrou que $84 \%$ das empresas financiadas e que implementaram inovações de produto realizaram inovações no âmbito da firma, enquanto apenas 36\% das empresas inovaram para o mercado (Gráfico 5). Em relação às inovações de processo, $88 \%$ dessas empresas realizaram inovações internas e somente $38 \%$ conceberam inovações para o mercado.

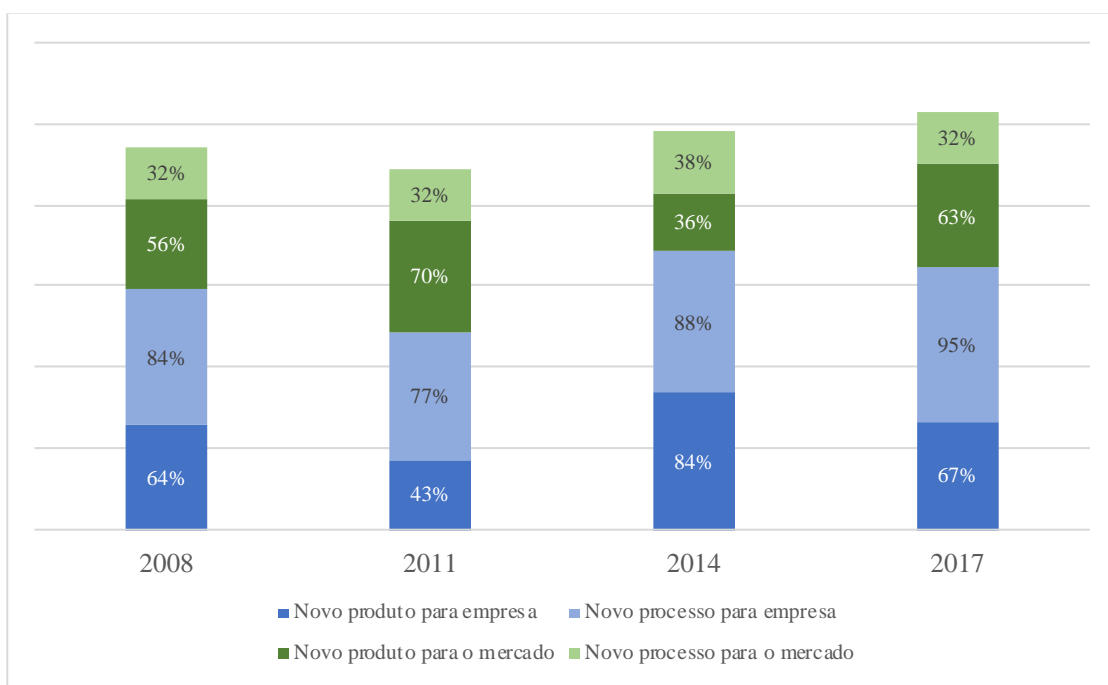

Gráfico 5 - Empresas farmacêuticas financiadas que implementaram inovações de produto ou processo Fonte: Elaboração própria com base em dados do IBGE (2017).

Na pesquisa de 2017, das empresas que implementaram inovações de produto no âmbito da firma, houve uma redução da frequência, passando para $67 \%$, enquanto o percentual de empresas que inovaram para o mercado nacional aumentou para 63\%. Apesar de positivo, o resultado de mais empresas disponibilizarem novos produtos para o mercado, $92 \%$ das que implementaram inovação declararam que é a própria empresa a única responsável pelo 
desenvolvimento da inovação. A situação sugere que a intenção de inovar não foi desenvolvida em cooperação com outras instituições. Essa característica dificulta o processo de acumular capacidades tecnológicas, necessário para gerar novos produtos ou processos para o mercado. A capacidade para inovar está relacionada com a competência das empresas em buscar novos conhecimentos.

No caso das inovações de processo, os números pouco alteraram nas duas últimas pesquisas, sendo ainda predominante a realização de inovações no nível da firma. A soma de $95 \%$ das empresas implementando um novo processo no âmbito da firma na pesquisa de 2017 corrobora a percepção de que essas inovações estão pouco relacionadas à redefinição da concepção de um novo produto para o mercado ou do seu processo de fabricação e corresponderam, sobretudo, por modernizações e por aquisições de máquinas e equipamentos.

A análise do perfil de esforço de inovação da indústria farmacêutica brasileira ao longo dos últimos 15 anos revelou mudanças importantes no tipo de investimento em atividades de inovação, sobretudo diante dos estímulos realizados pelo Estado. O subconjunto amostral das empresas farmacêuticas financiadas pelo BNDES e pela Finep representaram 56\% dos dispêndios nas atividades de inovação do setor, de acordo com a pesquisa de 2017. Esses investimentos sofreram algumas alterações estruturais, quando se analisa as últimas quatro edições da Pintec (IBGE, 2017). O Gráfico 6 apresenta o percentual dos gastos nas diversas atividades de inovação em relação à RLV dessas empresas. A altura da barra retrata o indicador intensidade de P\&D das empresas farmacêuticas financiadas, em que é possível observar uma tendência de redução. Em 2008, essa variável era de 7,2\%; em 2017, ela passou para 5,3\%. Observa-se, assim, que o elevado crescimento da RLV de $26 \%$ no período analisado pouco se traduziu em aumento nos investimentos em inovação suficientes para que fossem mantidos os níveis da intensidade de P\&D. Nesse contexto, as empresas apoiadas pelos BNDES e pela Finep convergiram para a média observada do setor, no que diz respeito ao indicador de intensidade de $\mathrm{P} \& \mathrm{D}$.

Em relação às despesas realizadas por essas empresas, houve um aumento expressivo na participação dos gastos em atividades internas de P\&D no total investido, passando de 20\% em 2008 para 66\% em 2017 (Gráfico 6). Apesar do avanço, os gastos nessa atividade em relação à RLV revelaram pouca mudança na estrutura dessa despesa, quando se observa as três últimas pesquisas, uma vez ter se mantido no nível de 3,4\% da RLV em média. Chama atenção nesse contexto o pouco dinamismo de mudanças tecnológicas dessas empresas, além do limitado efeito do apoio público para alterar o perfil dos investimentos nessa atividade.

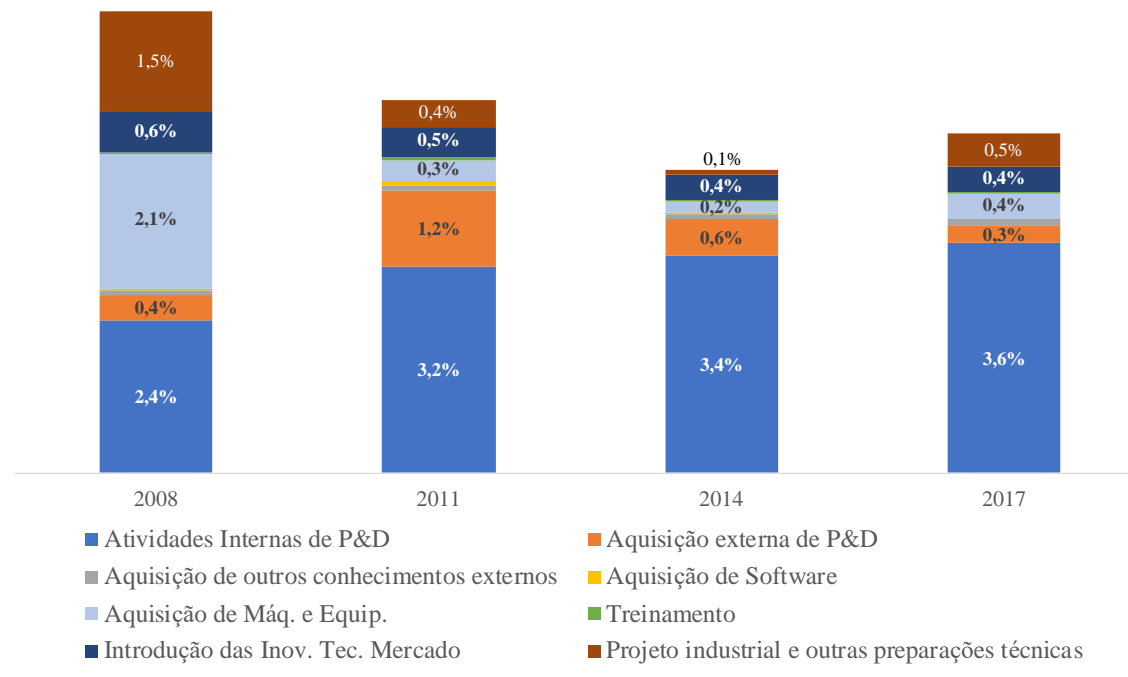

Gráfico 6 - Dispêndios nas Atividades de Inovação sobre a RLV das empresas farmacêuticas financiadas Fonte: Elaboração própria, com base em dados do IBGE (2017).

Ao analisar os dispêndios em máquinas e equipamentos em relação à RLV, percebe-se uma mudança significativa, apesar da certa estabilidade do número de empresas farmacêuticas financiadas que utilizaram o apoio do governo para esse fim. Em 2008, esses gastos representavam 2,1\% da RLV, enquanto em 2017, eles foram de 0,4\%. Em termos reais, essa variação foi cerca de $72 \%$, passando os gastos da ordem de R $\$ 375$ milhões em 2008 para pouco menos de R $\$ 105$ milhões em 2017. Ainda que as empresas tenham reduzido os dispêndios nessa atividade, adquirir bens de capitais para inovação ainda é um direcionador da estratégia de inovação dessa amostra de empresas. A Pintec de 2017 indicou que 80\% das empresas farmacêuticas apoiadas pelas duas instituições de fomento consideraram alta-média a importância de realizar esse tipo de gasto. 
As competências tecnológicas internas das empresas são complementadas pelo conhecimento gerado pelas atividades externas de P\&D. Terceirizar essas atividades é uma opção para reduzir o tempo do desenvolvimento de um produto, além de constituir uma fonte de conhecimento e de informação. Os dados mostram que os dispêndios na aquisição externa de $\mathrm{P} \& \mathrm{D}$ em relação à RLV, das empresas farmacêuticas financiadas, retornaram para os níveis da pesquisa de 2008, representando 0,4\% da RLV. As empresas parecem pouco interessadas em buscar esses conhecimentos e habilidades com instituições que poderiam possibilitar inovações radicais.

No tocante às fontes de informação utilizadas pelo grupo de empresas farmacêuticas financiadas pelo BNDES e pela Finep observa-se uma forte diversidade, ainda que o uso de informações oriundas dos departamentos de $\mathrm{P} \& \mathrm{D}$ das próprias empresas apresente a maior frequência (80\%). Em relação ao uso de fontes externas, a análise revela uma baixa interação com aquelas fontes especializadas de informação, tais que assegurariam conhecimentos mais avançados, como as empresas de consultoria (24\%), universidades (24\%) e centros tecnológicos $(36 \%)$. Conclui-se, nesse contexto, que a busca de conhecimentos externos que possibilitem inovações está aquém do esperado e, por isso, se mostra como uma limitação dessas empresas e contribui para a dificuldade do processo de aprendizagem tecnológica.

Nota-se, portanto, que as mudanças estruturais ocorridas estão relacionadas às maiores escalas de produção e modernização da organização. O crescimento financeiro dessas empresas e a facilidade em acessar as fontes de financiamento público não parece ter se traduzido em aumento das capacidades tecnológicas, de forma a torná-las mais competitivas. Os esforços em dominar por completo a produção de medicamentos genéricos e similares foram importantes e desafiaram essa indústria na busca por incorporar novas habilidades internas, no entanto ainda são insuficientes para acumulação de conhecimentos capazes de gerar novos produtos e tecnologias para o mercado nacional e internacional.

Em síntese, observa-se que esse segmento no país tem procurado aumentar os seus esforços de inovação, ainda que de forma lenta. O crescimento dos dispêndios em P\&D está associado à criação de competências internas, entretanto percebe-se ainda um tímido direcionamento dos investimentos para áreas de maior conhecimento do setor farmacêutico, que irão gerar um maior valor para as empresas desse setor.

\section{Conclusão: os limites do financiamento como indutor de novas capacidades tecnológicas}

O artigo procurou analisar, de maneira qualitativa, os efeitos dos empréstimos com taxas subsidiadas do BNDES e da Finep sobre os esforços de inovação das empresas farmacêuticas entre os anos de 2006 e 2018 . A partir de uma amostra selecionada de empresas, foram feitas análises dos objetivos dos projetos financiados e dos principais indicadores de inovação. Tendo essas informações como base, buscou discutir as consequências do financiamento no que diz respeito ao processo de acumulação de capacidades para inovação dessas empresas.

Verificou-se que, de forma geral, os investimentos públicos para inovação em todos os setores da economia oscilaram no período analisado. Entre 2006 e 2014, os recursos alocados pelo BNDES e pela Finep cresceram e alcançaram os maiores volumes de contratação e de desembolso. De 2014 até 2018, eles mudaram de direção e reduziram as novas contratações e liberações para projetos.

No caso do setor farmacêutico, a trajetória de contratação e desembolso foi, de certa forma, semelhante. Os dados mostraram que o crédito com taxas subsidiadas contribuiu para modernizar o parque produtivo de um pequeno grupo de empresas e, em menor escala, para elas alcançarem novos níveis de conhecimentos, especialmente no desenvolvimento de medicamentos genéricos e similares e no início da criação de capacidades para inovação em biotecnologia.

Durante a análise, constatou-se a predominância de inovações de produto e de processo no nível da firma. Esse tipo de inovação está associado à adoção de tecnologias incorporadas, seja reproduzindo inovações das farmacêuticas multinacionais seja implementando um novo equipamento no sistema produtivo. Essa situação revela que as intervenções de políticas pouco colaboraram para a criação de novas capacidades tecnológicas e para o aumento da competitividade dessas empresas.

Os dispêndios em atividades internas de P\&D em relação à RLV não se alteraram ao longo dos anos e os gastos com as atividades externas de $\mathrm{P} \& \mathrm{D}$ diminuíram. A capacidade para inovação de uma empresa exige investimentos significativos em $\mathrm{P} \& \mathrm{D}$ interno, além de projetos em conjunto com instituições especializadas. $\mathrm{O}$ artigo mostrou também a existência de pouca interação das empresas farmacêuticas financiadas pelo BNDES e pela Finep com outras fontes especializadas de conhecimento. $\mathrm{O}$ contato dessas empresas com outros atores do sistema nacional de inovação é fundamental, pois não apenas compensam as deficiências dos investimentos de P\&D interno, mas também certificam a competência dessas empresas em gerenciar uma rede de parceiros. Essa relação está ligada ao acesso por novos conhecimentos e habilidades. Dessa forma, identificou-se um efeito limitado do financiamento do BNDES e da Finep em alterar o perfil dos investimentos em inovação nas empresas e estimular a frequência das relações de cooperação. 
A performance financeira das empresas financiadas pelo BNDES e pela Finep, no que diz respeito à RLV, foi superior ao identificado no setor farmacêutico e na indústria de transformação, entretanto o resultado favorável não foi convertido em melhores níveis nos indicadores de esforços de inovação dessas empresas. A conclusão é de que o apoio público esteve concentrado em implementar políticas de inovação setoriais, sem incorporar a visão sistêmica que o setor de saúde exige. A exceção foi para o caso dos medicamentos biológicos, em que se observou uma visão coordenada entre o setor público e o produtivo com as necessidades de saúde, combinadas com o uso dos instrumentos de políticas de oferta e de demanda.

O presente artigo procurou contribuir para literatura de financiamento da inovação propondo uma nova forma de medir as capacidades tecnológicas, por meio dos objetivos dos projetos financiados pelo BNDES e pela Finep. Com o trabalho empírico, espera-se acrescentar essa possibilidade ao uso da medida convencional relativo aos gastos em P\&D.

A análise deste trabalho esteve concentrada no instrumento de crédito para inovação administrado pelo BNDES e pela Finep, refletindo a avaliação da eficácia desse mecanismo em estimular as inovações no setor farmacêutico. Expandir a análise para outros instrumentos de políticas, outros setores ou para outros países exigirá um conjunto de premissas melhor definidas. 
Technological capabilities of the Brazilian pharmaceutical industry: an analysis of the effects of BNDES and Finep financing

\begin{abstract}
:
The pharmaceutical industry is traditionally classified in the literature as a knowledge-based oligopoly, its dynamic being a direct function of investments in research, development and innovation. This article proposes to analyze in an integrated way the impact of financing with subsidized credits granted by the National Bank for Economic and Social Development (BNDES) and by the Brazilian Innovation Agency (Finep) on the creation of new technological capabilities in Brazilian pharmaceutical companies, between the years 2006 and 2018. The qualitative assessment of the effects of resources on the constitution of technical competences is done at the firm level, through information on projects financed by development institutions and indicators produced from Brazilian innovation research. The conclusion is that public credits for innovation have contributed to modernizing the production park and, to a lesser extent, for companies to achieve better levels of technological capabilities.
\end{abstract}

Keywords: innovation financing; technological capabilities; pharmaceutical industry. 


\section{Referências Bibliográficas}

AGÊNCIA NACIONAL DE VIGILÂNCIA SANITÁRIA. Anuário Estatístico do Mercado Farmacêutico, 2018. 20 dez. 2019. Disponível em: http://antigo.anvisa.gov.br/medicamentos/publicacoes?tagsName=cmed. Acesso em: 15 jul. 2020.

AGÊNCIA NACIONAL DE VIGILÂNCIA SANITÁRIA. Resolução RDC no 55, de 16 de dezembro de 2010. Disponível em: <http://bvsms.saude.gov.br/bvs/saudelegis/anvisa/2010/res0055_16_12_2010.html>. Acesso em: 20 ago. 2020.

APPELT, Silvia, GALINDO-RUEDA Fernando, GONZÁLES, Ana C., Measuring R\&D tax support: findings from the new OECD R\&D Tax Incentives Database. OECD Science, Technology and Industry Working Papers, Paris: OECD Publishing, 2019. https://doi.org/10.1787/d16e6072-en.

ARAÚJO, André Amaral. Desafios da Finep e o fomento à inovação. Revista USP, n. 93, p. 113-126, 2012.

ARROW, Kenneth. Economic welfare and the allocation of resources for invention. In: NELSON, R. (Ed.). The rate and direction of inventive activity. Princeton: Princeton University Press, 1962. p. 609-626.

BANCO NACIONAL DO DESENVOLVIMENTO ECONÔMICO E SOCIAL. BNDES. Disponível em: http://www.bndes.gov.br/acesso-a-informacao/transparencia. Acesso em: 07 jun. 2019.

BELL, Martin; PAVITT, Keith. The development of technological capabilities. In: HAQUE, I. U. Trade, technology and international competitiveness. Washington: Economic Development Institute of the World Bank, 1995. p. 69-100.

BORRÁS, Susana; EDQUIST, Charles. The choice of innovation policy instruments. Technological Forecasting and Social Change, v. 80, n. 8, p. 1513-1522, 2013.

BRASIL. Ministério da Ciência, Tecnologia e Inovação. Indicadores de Ciência, Tecnologia e Inovação - 2019. 2019. Brasília. Disponível em:

http://antigo.mctic.gov.br/mctic/export/sites/institucional/indicadores/arquivos/Indicadores_CTI_2019.pdf>. Acesso em: 27 out. 2020.

CASSIOLATO, José Eduardo; LASTRES, Helena Maria Martins. Sistemas de inovação e desenvolvimento: as implicações de política. São Paulo Perspec., São Paulo, v. 19, n. 1, p. 34-45, 2005.

CHAMINADE, Cristina; LUNDVALL, Bengt-Åke. Science, technology, and innovation policy: old patterns and new challenges. In: Oxford Research Encyclopedia of Business and Management. 2019.

CHAMINADE, Cristina; EDQUIST, Charles. Rationales for public policy intervention in the innovation process: a systems of innovation approach. In: KULHMAN, S.; SHAPIRA, P.; SMITS, R. (Eds.). The theory and practice of innovation policy: an international handbook. Cheltenham: Edward Elgar, 2010, p. 95 - 114.

COHEN, Wesley M.; LEVINTHAL, Daniel A. Absorptive capacity: a new perspective on learning and innovation. Administrative Science Quarterly, v. 35, n. 1, p. 128-152, 1990.

COLOMBO, Daniel Gama. Economic analysis of Innovation tax incentives in Brazil: essays on the impacts of law 11.196/05 on industrial innovation. 2017. Tese (Doutorado em Economia) - Faculdade de Economia, Administração e Contabilidade. Universidade de São Paulo, São Paulo, 2017.

COMEXSTAT. Ministério da Indústria. Comércio Exterior e Serviços. 2020. Disponível em: <http://comexstat. mdic. gov. br/pt/home>. Acesso em: 19 maio 2020.

COUTINHO, Luciano Galvão. Marcos e desafios de uma política industrial contemporânea. In: CASTRO, A. C. (Org.). Desenvolvimento em debate. Rio de Janeiro: Editora Mauad, 2002. p. 191-209.

CHRISTENSEN, Jesper. L. The role of finance in national systems of innovation. In: LUNDVALL, B-A. (Ed.). National Systems of Innovation: towards a theory of innovation and interactive learning. London: Pinter, 1992, p. 146168. 
DOSI, Giovanni. Finance, innovation and industrial change. Journal of Economic Behavior \& Organization, v. 13, n. 3, p. 299-319, 1990.

EDLER, Jakob; FAGERBERG, Jan. Innovation policy: what, why, and how. Oxford Review of Economic Policy, $v$. 33, n. 1, p. 2-23, 2017.

EDQUIST, Charles. Systems of innovation: perspectives and challenges. Oxford: Oxford University Press, 2006.

ERBER, Fábio Stefano. Desenvolvimento tecnológico e intervenção do Estado: um confronto entre a experiência brasileira e a dos países capitalistas centrais. Revista de Administração Pública, v. 14, n. 4, p. 10-72, 1980.

FIGUEIREDO, Paulo N. Aprendizagem tecnológica e inovação industrial em economias emergentes: uma breve contribuição para o desenho e implementação de estudos empíricos e estratégias no Brasil. Revista Brasileira de inovação, v. 3, n. 2, p. 323-361, 2004.

FINANCIADORA DE ESTUDOS E PROJETOS. Finep. 2019. Disponível em: <http://www.finep.gov.br/acesso-ainformacao-externo/transparencia/projetos-contratados-e-valores-liberados>. Acesso em: 11 maio 2019.

FREEMAN, Chris. The economics of industrial innovation. London/New York: Pinter Publishers, 1982.

FREEMAN, Chris; SOETE, Luc. A economia da inovação industrial. Campinas: Editora da UNICAMP, 2008.

FREITAS, Isabel. B. et al. Sectors and the additionality effects of R\&D tax credits: A cross-country microeconometric analysis. Research Policy, v. 46, n. 1, p. 57-72, 2017.

GADELHA, Carlos Augusto Grabois; VARGAS, Marco Antônio; MALDONADO, J. Barbosa, P. O Complexo EconômicoIndustrial da Saúde no Brasil: dinâmica de inovação e implicações para o Sistema Nacional de Inovação em saúde. Revista Brasileira de Inovação, v. 12, p. 251-282, 2013.

GADELHA, Carlos Augusto Grabois; TEMPORÃO, José Gomes. Desenvolvimento, Inovação e Saúde: a perspectiva teórica e política do Complexo Econômico-Industrial da Saúde. Ciência \& Saúde Coletiva, v. 23, p. 1891-1902, 2018.

HALL, Bronwyn; VAN REENEN, John. How effective are fiscal incentives for R\&D? A review of the evidence. Research Policy, v. 29, n. 4-5, p. 449-469, 2000.

INTERFARMA. Associação da Indústria Farmacêutica de Pesquisa. Guia 2019. 2019. Disponível em: <https://www.interfarma.org.br/guia/guia-2019/>. Acesso em: 9 fev 2020.

INSTITUTO BRASILEIRO DE GEOGRAFIA E ESTATÍSTICA. IBGE. Pesquisa Industrial de Inovação Tecnológica: Pintec 2008 a 2017. 2017. Disponível em: <https://www.ibge.gov.br/estatisticas/multidominio/ciencia-tecnologia-einovacao/9141-pesquisa-de-inovacao.html?=\&t=resultados>. Acesso em: 9 fev. 2020.

INSTITUTO BRASILEIRO DE GEOGRAFIA E ESTATÍSTICA. IBGE. Pesquisa Industria Anual - empresas: PIA 2007 a 2018. 2018. Disponível em: <https://www.ibge.gov.br/estatisticas/economicas/industria/9042-pesquisa-industrialanual.html?=\&t=0-que-e>. Acesso em: 9 fev. 2020.

KATZ, Jorge. Importación de tecnología, aprendizaje y industrialización dependiente. México: Fondo de Cultura Económica, 1976.

LALL, Sanjaya. Technological capabilities and industrialization. World Development, v. 20, n. 2, p. 165-186, 1992.

LIST, Friederich. The national system of political economy. London: Longman. 1904 (Original work published 1841).

LUNDVALL, Bengt-Åke. National Systems of Innovation: towards a theory of innovation and interactive learning. London: Pinter Publishers, 1992. 
LUNDVALL, Bengt-Åke. Innovation and competence building in the learning economy-implications for innovation policy: Kunnskapsdugnaden 2008-Delprojekt om Kunnskap og læringsøkonomi, 2008.

MAZZUCATO, Mariana. Mission-oriented innovation policies: challenges and opportunities. Industrial and Corporate Change, v. 27, n. 5, p. 803-815, 2018.

MELO, Luiz Martins. O financiamento da inovação industrial. 1994. 341f. Tese (Doutorado em Economia). Instituto de Economia da Universidade Federal do Rio de Janeiro, Rio de Janeiro, 1994.

MELO, Luiz Martins. Financiamento à inovação no Brasil: análise da aplicação dos recursos do Fundo Nacional de Desenvolvimento Científico e Tecnológico (FNDCT) e da Financiadora de Estudos e Projetos (FINEP) de 1967 a 2006.

Revista Brasileira de Inovação, v. 8, n. 1, p. 87-120, 2009.

NATIONAL SCIENCE BOARD, National Science Foundation. 2020. Science and engineering indicators 2020: The state of U.S. science and engineering. NSB-2020-1. Alexandria, VA. Disponível em: <https://ncses.nsf.gov/pubs/nsb20201/>. Acesso em: 9 fev. 2020.

NELSON, Richard; WINTER, Sidney. An evolutionary theory of economic change. Cambridge, Mass: Harvard University Press, 1982.

NELSON, Richard; Why do firms differ and how does it matter? Strategic Management Journal, v. 12, special issue, p. 61-74, 1991.

OECD. Oslo Manual 2018: Guidelines for collecting, reporting and using data on innovation. Organisation for Economic Co-operation and Development, 2018.

O' SULLIVAN, Mary. Finance and innovation. In: FAGERBERG, J.; MOWERY, D.; NELSON, R., R. The Oxford Handbook of Innovation. Oxford: Oxford University Press, 2005. p. 240-265.

RAPINI, Márcia Siqueira. 0 financiamento aos investimentos em inovação no Brasil. 2010. Tese (Doutorado em Economia) - Instituto de Economia, Rio de Janeiro, 2010.

RIBEIRO, Eduardo Pontual; DE NEGRI, João Alberto. Public credit use and manufacturing productivity in Brazil. $2009 . \quad$ Disponível em: <https://www.researchgate.net/profile/Eduardo_Ribeiro8/publication/264849408_Public_Credit_Use_and_Manufac turing_Productivity_in_Brazil/links/542d3f4f0cf27e39fa94220a/Public-Credit-Use-and-Manufacturing-Productivity-inBrazil.pdf>. Acesso em: 24 Ago. 2020.

ROSENBERG, Nathan. Why do firms do basic research (with their own money)? Research Policy, v.19, n. 2, p. 165-174, 1990.

SCHUMPETER, Joseph Alois. Teoria do Desenvolvimento Econômico. São Paulo: Editora Abril, 1982.

STIGLITZ, Joseph. E., JARAMILLO-VALLEJO, Jaime; PARK, Yung Chai. The role of the state in financial markets. The World Bank Economic Review, v. 7, n._1, p. 19-52, 1993. doi: https://doi.org/10.1093/wber/7.suppl_1.19.

TIGRE, Paulo Bastos; NASCIMENTO, Caio Victor Machado França; COSTA, Laís Silveira. Janelas de oportunidades e inovação tecnológica na indústria brasileira de medicamentos. Cadernos de Saúde Pública, v. 32, supl. 2, 2016. doi: http://dx.doi.org/10.1590/0102-311X00103315.

WATERS, Ryan.; URQUHART, Lisa. Evaluate Pharma World Preview 2019, Outlook to 2024. London: Evaluate Ltd, 2019.

VARGAS, Marco; ALMEIDA, Águida Cristina Santos; GUIMARÃES, Ana Luiza Coelho. Parcerias para o desenvolvimento produtivo (PDPs/MS): contexto atual, impactos no sistema de saúde e perspectivas para a política industrial e tecnológica na área da saúde. Rio de Janeiro: Fiocruz, 2017.

ZYSMAN, John. Governments, markets and growth: financial systems and the politics of industrial change. Nova York: Cornell University Press, 1983. 